\title{
Chilling of Endodormant Peach Propagules: I. Seed Germination and Emergence
}

\author{
James W. Frisby ${ }^{1}$ and Schuyler D. Seeley ${ }^{2}$ \\ Plants, Soils, and Biometeorology Department, Utah State University, Logan, UT 84322-4820
}

\begin{abstract}
Additional index words. Prunus persica, temperature responses, forcing, chilling requirement, dormancy
Abstract. We compared peach [Prunus persica (L.) Batsch cv. Johnson Elberta] seed germination (G) and seedling emergence (E) after various stratification (St) treatments. Treatments were arranged in factorial combinations of five St durations ( 20 to 60 days) at eight constant temperatures (0 to 18C) in a completely randomized design followed by repeated measures during forcing time. $G$ and $E$ were recorded every 5 days during forcing. Seed St at 0 to $10 \mathrm{C}$ and 0 to $14 \mathrm{C}$ promoted $G$ and $E$, respectively. $G$ and $E$ increased with longer $S t$ treatments at promoting temperatures. There was a weak correlation between $G$ and $E$ averaged over the forcing measurements $\left(r^{2}=0.54\right)$. The best correlation was between $E$ after 15 days and $G$ after 10 days $\left(r^{2}=0.83\right)$. The results indicate that $G$ and $E$ in peach are not identical indicators of endodormancy (ED) release and should not be used interchangeably. Forcing times must be considered when making comparisons between $G$ and $E$.
\end{abstract}

Peach seeds must be stratified between 0 and 10C to remove ED (Seeley and Damavandy, 1985). Seeds have been used to study ED because they are small and easy to handle. Buds and seeds are reported to have similar chilling requirements in apple (Malus dometica Borkh.) (Pastemak-Orawiec and Powell, 1983a, 1983b), pear (Pyrus communis L.) (Westwood and Bjornstad, 1968), and peach (Chang and Werner, 1984).

$\mathrm{G}$ (radicle growth) and E (shoot appearance after planting) are often used interchangeably in dormancy studies. However, these phenomena may not be identical indicators of the seed chilling process and ED release. We also compared $G$ and $E$ of peach seeds with initial seedling growth (first season), budbreak and growth of seedlings (physiologically dwarfed to near normal), and terminal shoot growth of mature cuttings after seeds, seedlings, andcuttings were exposed to various chilling treatments (Frisby and Seeley, 1993).

\section{Materials and Methods}

'Johnson Elberta' peaches were harvested when ripe in Fall 1986 from the Utah State Univ. Experiment Station, Kaysville. Pits were removed and allowed to dry. Dry pits were cracked with a hand press to remove the endocarp, and seeds were placed in mason jars for storage at room temperature. Only seeds with unbroken integuments were used.

Treatments were arranged in factorial combinations of five St durations (20,30, 40, 50, and 60 days) at eight constant temperatures $(0,2,4,6,8,10,14$, and $18 \mathrm{C})$ in a completely randomized design followed by repeated measures during forcing time at 5-day intervals. Five replications of 10 seeds were used for each treatment combination. Each replication was placed on a paper blotter (Steel Blue, $77 \times 77 \mathrm{~mm}, 10 \mathrm{~mm}$ triangle removed from each comer, Anchor Paper, St. Paul, Minn.) in a plastic petri dish $(100 \times 15 \mathrm{~mm})$.

Received for publication 4 Feb. 1992. Accepted for publication 1 Sept. 1992 This report is based, in part, on research conducted and supported as part of SAES Western Regional Research Project W-130. Utah Agr. Expt. Sta. Paper no. 4267. The use of trade names does not imply endorsement of the products used nor criticism of similar ones not mentioned. The cost of publishing this paper was defrayed in part by the payment of page charges. Under postal regulations, this paper therefore must be hereby marked advertisement solely to indicate this fact 'Graduate Research Assistant.

${ }^{2}$ Professor.
Six milliliters of N-trichlormethylthio-4-cyclohexene-1,2dicarboximide (Captan) (50 WP, Stauffer Chemical, Westport, Corm.) suspension at $0.3 \%$ a.i. (w/v) were added to each petri dish. Petri dishes were sealed with Parafilm to prevent water loss. Petri dishes were randomly placed in cardboard boxes $(80 \times 320 \times 320$ $\mathrm{mm}$ ) and covered with aluminum foil to exclude light. Boxes were placed in constant temperature chambers made of $50 \mathrm{~mm}$ thick high density extruded polystyrene foam $(0.6 \times 1.2 \times 1.2 \mathrm{~m}$ for 2 to $14 \mathrm{C}, 0.7 \times 0.6 \times 1.0 \mathrm{~m}$ for 18 and $20 \mathrm{C}, 0.58 \times 0.86 \times 0.33 \mathrm{~m}$ for $0 \mathrm{C}$ ) in a cold room set at $0 \mathrm{C}$. The $0 \mathrm{C}$ chamber was contained inside a refrigerator in the cold room. Since the $0 \mathrm{C}$ chamber was too small for a cardboard box, petri dishes in this chamber were wrapped in aluminum foil. Cardboard boxes were elevated to allow air circulation. Constant temperatures (less than $\pm 0.032 \mathrm{C}$, daily $95 \%$ confidence interval) were maintained with proportional controllers (Model 70-A, RFL 903 10, Dowty Electronics, Brandon, Vt.) that used 200W light bulbs as the heat source.

Germination. At appropriate durations, the boxes were removed. Replications for that duration were removed and placed in a 20C chamber. Remaining petri dishes were returned to the St chambers.

$\mathrm{G}$ was observed through the petri dish cover at $0,5,10$, and 15 days after St. A seed was considered germinated when radicle growth was at least $2 \mathrm{~mm}$. A factorial univariate repeated measures analysis of variance (ANOVA) was used to analyze the $\mathrm{G}$ data (Littell, 1989).

Emergence. Petri dishes were prepared at different times then placed in the chambers so that all the St treatments ended simultaneously. This provided a similar growth environment for all treatments. Seeds were prepared as those that were used in the G experiment, except the seeds were soaked overnight in the captan solution before they were placed in the petri dishes. When subsequent petri dishes were prepared at each duration, existing petri dishes were re-randomized with the new ones.

After St treatment, petri dishes were placed in a large box in the greenhouse for 1 day before the seeds were planted (4 May 1987). The seeds from each petri dish wereplanted in standard plastic flats $(6 \times 25 \times 52 \mathrm{~cm})$ that contained soilless medium $(1$ peat : 1 vermiculite : 0.5 perlite, by volume). Seeds from each petri dish were planted $3 \mathrm{~cm}$ deep in two adjacent rows of five seeds each.

Abbreviations: E, emergence; ED, endodormancy; G, germination; St, stratification. 


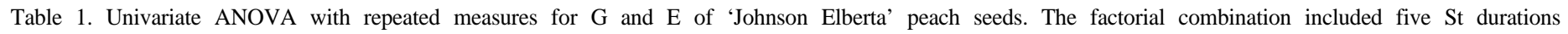
$(20,30,40,50$, and 60 days) at seven temperatures $(0,2,4,6,8,10$, and 14C) in a completely randomized design with repeated measures forcing time. Forcing times used for analysis were 5, 10, and 15 days for $\mathrm{G}$ and 10, 15, 20, and 25 days for E. ${ }^{2}$ Linear and polynomial trend analysis is provided for main effects and important interactions.

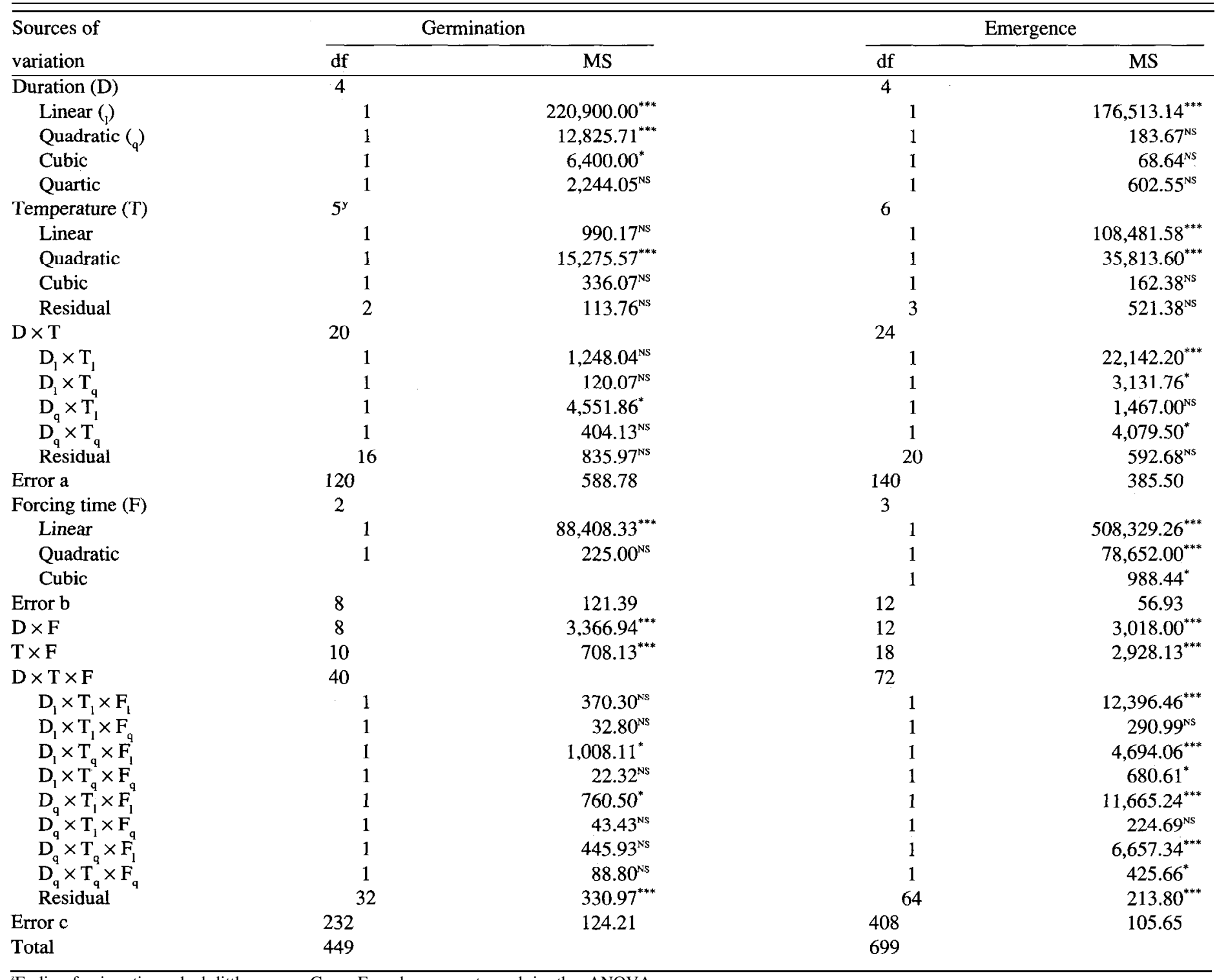

${ }^{2}$ Earlier forcing times had little or no $\mathrm{G}$ or $\mathrm{E}$ and were not used in the ANOVA.

${ }^{\mathrm{y}}$ The ANOVA for $\mathrm{G}$ did not include seeds treated at $14 \mathrm{C}$.

${ }^{\text {NS, }, * * * * * *}$ Nonsignificant or significant at $P=0.05,0.01$, or 0.001 , respectively.

Four or five replications were planted in each flat.

The greenhouse was maintained at 27/21C (day/night). A 16-h photoperiod was provided by natural sunlight supplemented with artificial light provided by $1000 \mathrm{~W}$ high pressure sodium lamps. The flats were watered with tap water when the top of the medium appeared dry.

E was recorded at 5, 10, 15, 20, and 25 days during forcing in the greenhouse. A seed (seedling) was considered to have emerged when the shoot appeared at or above the surface of the medium. Factorial univariate repeated measures ANOVA was also used for the E data (Littell, 1989). Percent G and E values were correlated using linear and polynomial regression.

\section{Results and Discussion}

No G occurred after St at 14 or $18 \mathrm{C}$. Little G occurred during St.
No E occurred after seed St at $18 \mathrm{C}$ or within 5 days after planting. These temperatures and forcing times were not used in calculating the ANOVA values (Table 1). All sources of variation were significant for $\mathrm{G}$ and $\mathrm{E}$. Due to the many temperature treatments, all replications for each temperature were treated in one temperature controlled chamber simultaneously. We understand that this underestimated the error terms for the true variability of the systems. However, the probabilities for the F tests were extremely low, indicating significance with much larger error terms (Table $1)$.

The main effect of St duration indicated that $\mathrm{G}$ increased linearly with longer St times (Table 1). The main effect of St temperature indicated that seed $\mathrm{G}$ varied quadratically between 0 and 10C (Table 1). The significant interaction between St duration, St temperature, and forcing time for G illustrates the complexity of the chilling process that promotes $G$ (Fig. 1). St at promoting 

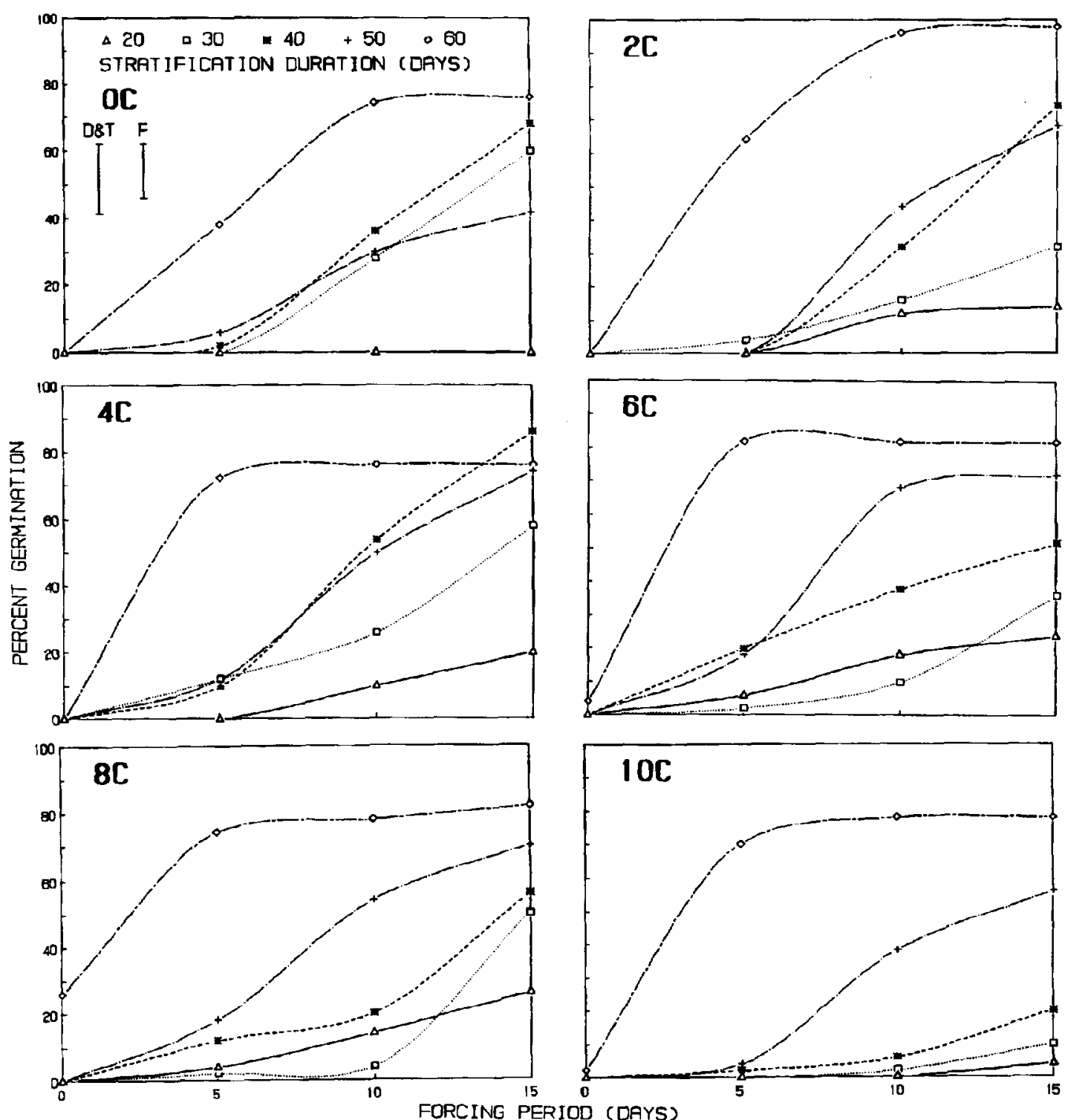

Fig. 1. Three way interaction between St duration (20, 30, 40, 50, and 60 days), temperature ( $0,2,4,6,8$, and 10C), and forcing period (5, 10, and 15 days) on 'Johnson Elberta' seed germination $(\% \mathrm{G})$. No G occurred when seeds were stratified at 14 or $18 \mathrm{C}$. F $=$ LSD 0.05 bar for comparisons among the forcing periods when temperature and duration are fixed. D\&T = LSD 0.05 bar for differences among duration and temperature combinations when forcing periods are fixed. Trend analysis is provided in Table 1.

temperatures for longer times increased seed G. Improved seed G was evidenced by earlier $\mathrm{G}$ and by higher final percentages. Seed $\mathrm{G}$ increased greatly between 50 and 60 days of St. Seeds stratified at $2 \mathrm{C}$ for 60 days reached the highest percent $\mathrm{G}$ obtained $(98 \%)$. Only seeds stratified at $8 \mathrm{C}$ for 60 days had appreciable G during St, suggesting significant heat unit accumulation after 50 days of $\mathrm{St}$ at $8 \mathrm{C}$.

The main effect of St duration indicated that $\mathrm{E}$, like $\mathrm{G}$, increased linearly with longer St times (Table 1). The main effect of St temperature also indicated a quadratic response between 0 and $14 \mathrm{C}$ (Table 1). The three way interaction (Fig. 2) indicated that $\mathrm{E}$ increased with longer St time at temperatures between 0 to $14 \mathrm{C}$. E improved after longer St times by reaching higher $\mathrm{E}$ percentages in shorter forcing times. St at 0 and $2 \mathrm{C}$ were the best treatments for St durations shorter than 40 days. Temperatures $\geq 4 \mathrm{C}$ led to increasingly lower $\mathrm{E}$ percentages, but $\mathrm{E}$ consistently increased with longer St treatments. Seed St at $14 \mathrm{C}$ did not promote appreciable $\mathrm{E}$ until the seeds were stratified for 50 and 60 days. Even then, E was significantly slower than E of seeds stratified at lower temperatures.

Interestingly, seeds did not germinate, but some seedlings emerged within 15 days of forcing when stratified at 14C. Similarly, Zigas and Coombe (1977) reported that even though some peach embryos did not germinate within 10 days of forcing, these embryos would invariably produce seedlings after planting. Apparently, soil or medium conditions are more promotive of $G$ and $\mathrm{E}$ than conditions inside a petri dish at isothermal temperatures.

Correlations were low between $\mathrm{G}$ and $\mathrm{E}$ percentages averaged over forcing periods [a value similar to the sum value suggested by Timson (1965)] (Fig. 3A). The highest correlation was obtained when $E$ results recorded at 15 days forcing were compared to $G$ results at 10 days (Fig. 3B). The relationship was usable at $<70 \%$ $\mathrm{G}$ and $<90 \% \mathrm{E}$. Yet, $\mathrm{G}$ results recorded at 10 days of forcing did not correlate any better than the average $G$ during forcing (data not presented). The $\mathrm{E}$ percentage at 15 days of forcing was more accurate than an average or summed value (data not presented). 

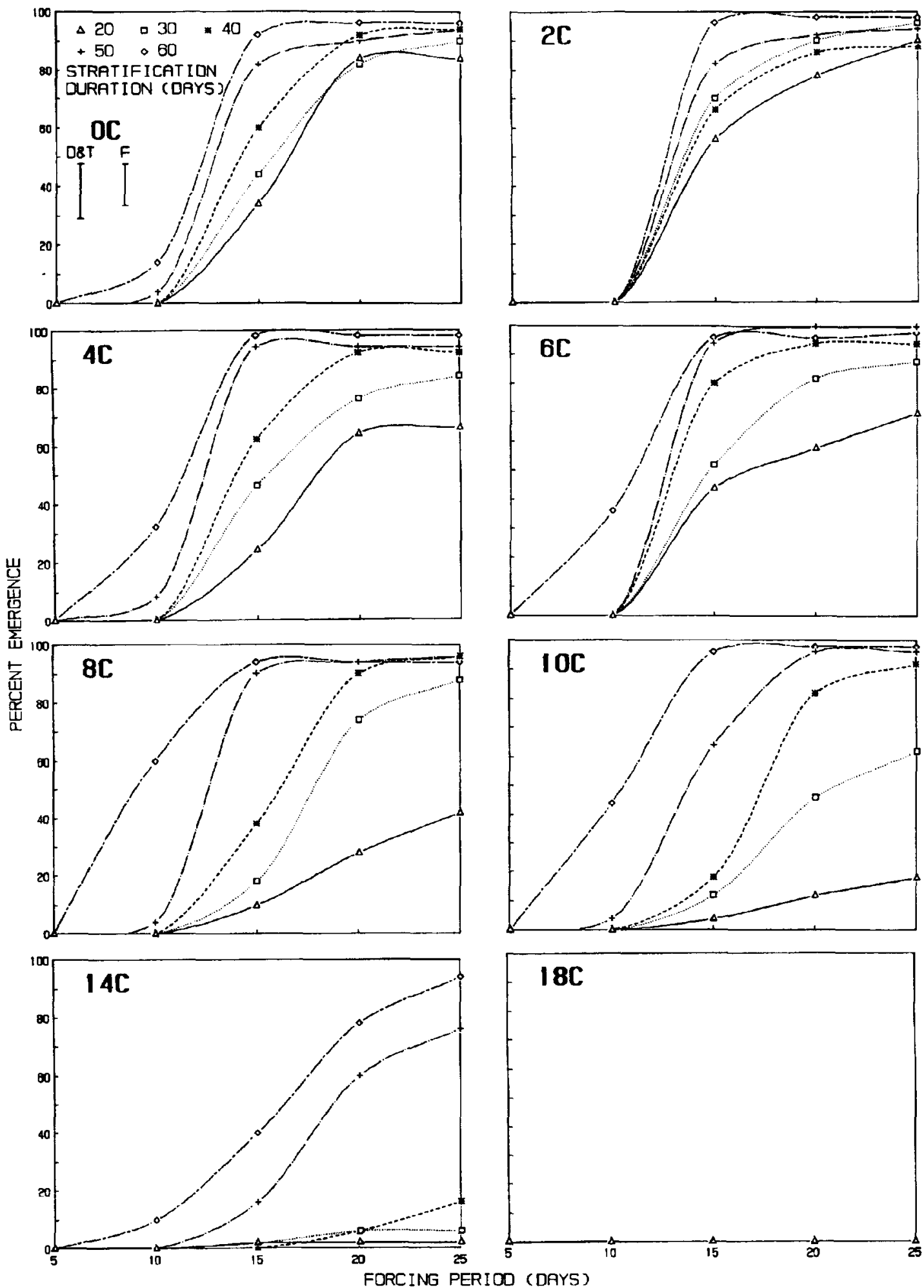

Fig. 2. Three way interaction between St duration $(20,30,40,50$, and 60 days), temperature $(0,2,4,6,8,10$, and $14 \mathrm{C})$, and forcing period (10, 15, 20, and 25 days) on 'Johnson Elberta' seedling emergence $(\% \mathrm{E})$. No E occurred when seeds were stratified at $18 \mathrm{C}$. F=LSD 0.05 bar for comparisons among forcing periods whentemperatures and duration are fixed. D\&T $=$ LSD 0.05 bar for differences among duration and temperature combinations when forcing periods are fixed. Trend analysis is provided in Table 1.

In summary, $\mathrm{G}$ and $\mathrm{E}$ increased with longer St time at temperatures from 0 to $10 \mathrm{C}$. $\mathrm{G}$ and $\mathrm{E}$ did not correlate well, except for $\mathrm{E}$ at 15 days and $\mathrm{G}$ at 10 days forcing. Therefore, $\mathrm{G}$ and $\mathrm{E}$ can not be used interchangeably to determine dormancy status of 'Johnson Elberta' peach seeds. The largest $\mathrm{G}$ increment occurred between
50 and 60 days of $\mathrm{St}$ at temperatures between 0 and 10C. Contrastingly, the largest increases in E occurred from 0 to $6 \mathrm{C}$ during the first 20 days of St. The optimum St temperature range for $\mathrm{G}$ was between 2 to $6 \mathrm{C}$ and the optimum range for $\mathrm{E}$ was 0 to $2 \mathrm{C}$, with 4 and $6 \mathrm{C}$ being slightly less effective. Our results show 

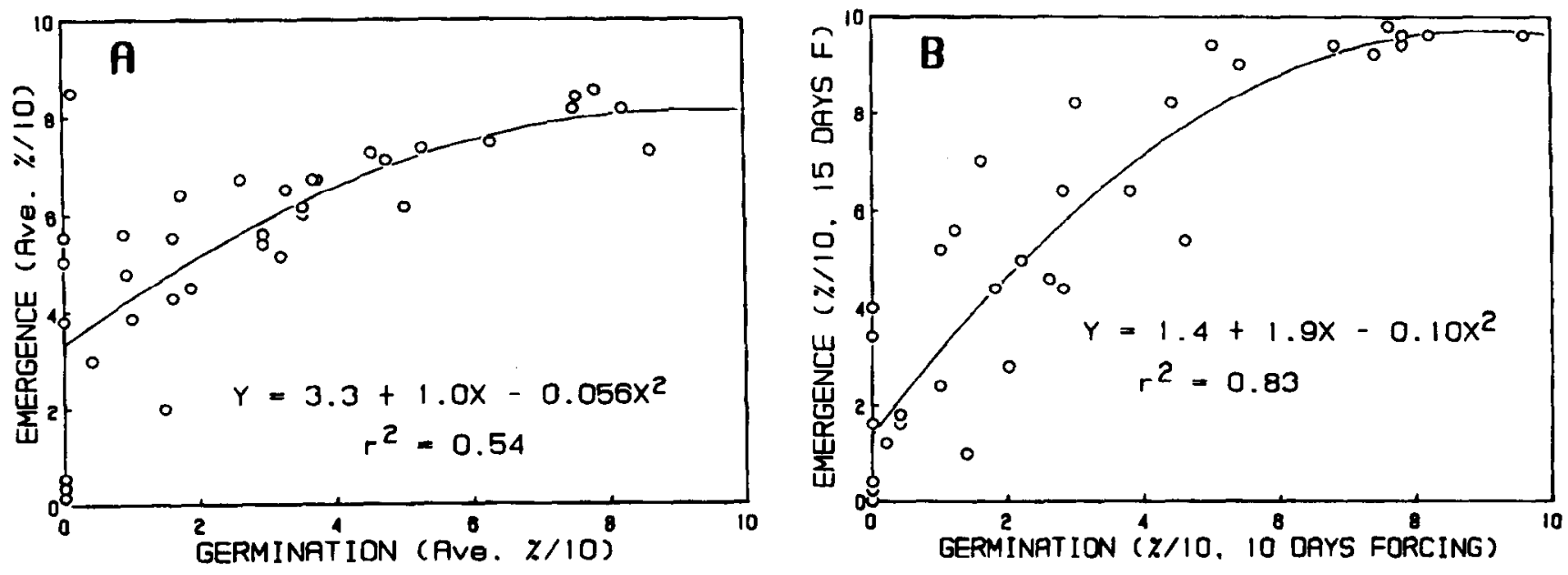

Fig. 3 Correlations between percent $\mathrm{G}$ and $\mathrm{E}$ of 'Johnson Elberta' peach seeds. (A) Correlation between $\mathrm{G}$ averaged over three forcing periods (5, 10 , and 15 days) and $\mathrm{E}$ averaged over four forcing periods $(10,15,20$, and 25 days). (B) Correlation between $\mathrm{G}$ after 10 days forcing and $\mathrm{E}$ after 15 days forcing.

definite differences in temperature responses during St for promotion of $\mathrm{G}$ in a petri dish at isothermal conditions and seedling $\mathrm{E}$ in a medium in the greenhouse (not isothermal),

\section{Literature Cited}

Chang, S. and D.J. Werner. 1984. Relationship of seed germination and respiration during stratification with cultivar chilling requirement in peach. J. Amer. Soc. Hort. Sci. 109:42-45.

Frisby, J.W. and SD. Seeley. 1993. Chilling of endodormant peach propagules: V. Comparisons between seeds, seedlings, and cuttings. J. Amer. Soc. Hort. Sci. 118:269-273.

Littell, R.C. 1989. Statistical analysis of experiments with repeated measurements. HortScience 24:37-40.

Pasternak-Orawiec, G. and L.E. Powell. 1983a. Changes in abscisic acid and gibberellin during the stratification of low and high chilling apple seeds. HortScience 18:560. (Abstr.)

Pastemak-Orawiec, G. and L.E. Powell. 1983b. Chilling requirements for seeds of late-blooming apples. HortScience 18:561. (Abstr.)

Seeley, S.D. and H. Damavandy. 1985. Response of seed of seven deciduous fruits to stratification temperatures and implications for modeling. J. Amer. Soc. Hort. Sci. 110:726-729.

Timson, J. 1965. New method of recording germination data. Nature 207:216-217.

Westwood, M.N. and H.O. Bjornstad. 1968. Chilling requirements of dormant seeds of 14 pear species as related to their climatic adaptation. Proc. Amer. Soc. Hort. Sci. 92: 141-149.

Zigas, R.P. and B.G. Coombe. 1977. Seedling development in peach, Prunus persica (L.) Batsch. II Effects of plant growth regulators and their possible role. Austral. J. Plant Physiol. 4:359-369. 